\title{
Envelope Protection and Atmospheric Disturbances in Icing Encounters
}

\author{
Jason Merret ${ }^{*}$, Kishwar N. Hossain ${ }^{*}$, and Michael B. Bragg ${ }^{+}$ \\ University of Illinois at Urbana-Champaign
}

\begin{abstract}
Research is reported on aircraft performance and control in icing, related to the development of Smart Icing Systems for improved flight safety. Microburst and gravity wave atmospheric disturbances were modeled, and their effects on the aircraft performance and control were compared to that of an icing encounter. Simulations were run using a six degreeof-freedom computational flight dynamics model. The study showed that microbursts could easily be differentiated from icing encounters. On the other hand gravity waves are more difficult to differentiate. A plan was formulated for developing an envelope protection system effective in icing conditions. Two dimensional airfoil data were analyzed and showed promising results for prediction of envelope limit exceedence. Changes in unsteady hinge moments were especially effective in predicting stall.
\end{abstract}

\section{NOMENCLATURE}

$\mathrm{C}_{\mathrm{d}} \quad$ Airfoil drag coefficient

$\mathrm{C}_{\mathrm{h}} \quad$ Airfoil hinge moment coefficient

$\mathrm{C}_{\mathrm{h}, \mathrm{RMS}} \quad$ Airfoil unsteady hinge moment coefficient

$\mathrm{C}_{1} \quad$ Airfoil lift coefficient

$\mathrm{C}_{\mathrm{L}} \quad$ Aircraft lift coefficient

$\mathrm{C}_{\mathrm{D}} \quad$ Aircraft drag coefficient

$\mathrm{C}_{\mathrm{M}} \quad$ Aircraft pitching moment coefficient

$F_{x}, F_{y}, F_{z} \quad$ Forces on the aircraft

AOA Angle of attack

FDC Flight dynamics code

IMS Ice management system

IPS Ice protection system

SIS Smart icing systems

c Model chord length

$\mathrm{k} \quad$ Protuberance height

$\mathrm{p}, \mathrm{q}, \mathrm{r} \quad$ Aircraft angular rates

$r \quad$ Radial distance

s Model coordinate in surface length

$\mathrm{q}_{\mathrm{g}} \quad$ Effective pitch rate due to gust velocity

$\mathrm{u} \quad$ Control vector

z $\quad$ Altitude $z^{*}$

$\mathrm{H}$

$\mathrm{R} \quad$ Radius of the downburst shaft

$\mathrm{V} \quad$ Airspeed

$\mathrm{x} \quad$ State Vector

$\mathrm{x}_{\text {fast }} \quad$ Fast state vector

$\mathrm{X}_{\text {slow }}$

$\mathrm{y}_{\mathrm{p}}$

$\mathrm{y}_{\text {plimit }}$

$\alpha$

$\beta$

$\delta_{\mathrm{a}}$

$\delta_{\mathrm{e}}$

$\delta_{\mathrm{p}}$

$\delta_{\mathrm{r}}$

$\varepsilon$

$\gamma$

$\lambda$

$\phi$

$\theta$

$\eta$

$\eta_{\text {ice }}$

\section{INTRODUCTION}

Aircraft performance and stability and control can change significantly during an icing event. This can occur with or without the ice protection system operating. These changes, particularly the degradation in aircraft control, have resulted in aircraft incidents and accidents. For commercial aircraft, where revenue and schedules must be maintained, and other iceprotected aircraft, better systems are needed to allow the vehicle to operate safely under these conditions. This paper is part of the Smart Icing System Research program being conducted at NASA, the University of Illinois, and Ohio State University to address the need for safer flight in icing conditions.

This research program was originally reviewed and explained by Bragg in $1998^{1}$ and a more recent

\footnotetext{
* Graduate Research Assistant, Department of Aeronautical and Astronautical Engineering, Member AIAA.

${ }^{+}$Professor and Head, Department of Aeronautical and Astronautical Engineering, Associate Fellow AIAA.
}

Copyright 2002 @ by Michael B. Bragg. Published by American Institute of Aeronautics and Astronautics, Inc. with permission. 
program review was presented in $2002 .^{2}$ Basically, the concept is to measure in flight the effect of the ice on performance and control and to use this information in a human-centered autonomous system to control the IPS, perform envelope protection, and adapt the flight controls. The first step, to measure in flight the effect of the ice on performance and control, is referred to as icing characterization. Initial development of the characterization and envelope protection systems has been done through simulation. A six degree-offreedom simulation has been developed for this purpose. ${ }^{3,4}$ This paper presents continued development of this capability and uses it to explore the effect of atmospheric disturbances on characterization and initial research on envelope protection.

Although icing is a very important concern for aircraft, it is not the only atmospheric condition that affects an aircraft. Wind shear has been a known cause of aircraft accidents for more than 30 years. From 1964 to 1985 over 26 accidents have been attributed to wind shear. ${ }^{5}$ The initial models used to represent microbursts in simulations were quite simple. These models used step and sine functions to represent the winds generated by the microburst. Osegeura and Bowles ${ }^{6}$ developed a simple, but accurate model in 1988 that used a number of different atmospheric data sets. Additional models that use single and double vortex rings have also been developed that are more accurate, but are also much more complex. A number of strategies have been developed for recovery in microbursts. Mulgund and Stangel's research demonstrated that the optimum recovery was a full thrust command followed by a pitch angle of $15 \mathrm{deg} .^{5}$

More recently gravity waves have surfaced as an atmospheric disturbance of interest. Initially, these were only of academic interest, but it is now known that a considerable amount of energy and momentum is carried by these waves. Gravity waves are typically in the upper atmosphere, but are also present in the troposphere, mainly generated by mountains. These waves vary in wavelength from 1 to 1000 kilometers with the wind velocity amplitudes of centimeters per second. In the upper atmosphere the velocity amplitudes can reach values in the range of meters per second. Unfortunately, the extent of our knowledge of gravity waves is still relatively small, and therefore the models used are simple sine waves. ${ }^{7,8}$

Envelope protection is an integral aspect of flight safety operations. All aircraft are equipped with some form of envelope protection. Commercial aircraft such as the Boeing 777 and Airbus 320 take advantage of the fly-by-wire control systems using preset limits for parameters such as the angle of attack, bank angle, etc. ${ }^{9}$ Commuter aircraft such as the ATR 72 are equipped with stall protection systems (SPS) to prevent the pilot from exceeding preset limits. ${ }^{10}$
Due to the numerous icing related accidents the envelope protection systems aboard some aircraft were modified to account for the performance degradation due to ice accretion. The ATR 72 SPS operates in conjunction with the IPS to reduce the angle of attack limit from $18.1^{\circ}$ to a predetermined value of $11.2^{\circ}$ in icing conditions. ${ }^{10}$ However, this value is not modified based on the actual ice accretion although the performance degradation may cause the aircraft to stall at a much lower AOA. For example in the ATR accident of 1994 the roll anomaly occurred at an angle of attack of $5^{\circ} .^{10}$ In order to ensure the safety of an aircraft during icing conditions, existing envelope protection systems need to be modified to smarter versions, which would update the envelope limits in real-time depending on the aircraft state and icing severity.

Horn et al. ${ }^{11}$ developed a system for flight envelope cueing of tilt rotor aircraft using parameter prediction algorithms based on available sensor data and control surface deflections. The system utilizes the functional dependence of the equations of motion and the envelope limits on the aircraft state. However at present this system is limited to providing envelope protection for a clean aircraft only because under icing conditions the equations of motion and the envelope limits become dependent on the icing severity. Hence, the system needs to be modified in order to account for icing.

The effect of icing and other atmospheric disturbances will be covered in the paper. The paper will briefly cover the effect of microbursts and will primarily focus on gravity waves and icing. Modifications have been applied to the formulation of the envelope protection system. The paper also includes discussions of the research completed to determine the envelop limits of an iced aircraft as functions of ice accretion and the use of unsteady hinge moment as an effective icing parameter.

\section{ENVELOPE PROTECTION}

The objective of the SIS envelope protection system is to ensure the safe operation of an aircraft under icing conditions within a reduced flight envelope. The aerodynamics and flight mechanics of an iced aircraft need to be analyzed comprehensively, in terms of such parameters as minimum speed (maximum $\alpha$ ), maximum bank angle, maximum control deflection, etc, to determine the limits for safe flight.

The aerodynamic and flight mechanics analysis was derived not only from the need to define the reduced flight envelope due to ice, but also from the information needed for the pilot displays and the 
control requirements to enforce the iced flight envelope.

\subsection{Critical Parameters}

Certain critical parameters must be chosen in order to formulate the proposed envelope protection scheme. Aerodynamically the aircraft should be protected from wing stall, horizontal tail stall, roll upset and loss of longitudinal and lateral control.

The critical parameters have thus been identified as, $\alpha_{w}, \alpha_{t}$, and $\phi$. As discussed below boundaries need to be defined for these parameters as functions of ice accretion, aerodynamic parameters, and stability and control derivatives.

\subsection{Icing Envelope}

Conventional envelope protection, where predetermined limits are assigned to parameters such as the angle of attack, bank angle etc., is not always effective in icing conditions. This is because the performance of the aircraft changes as a function of the icing severity. Hence, it is essential to introduce the concept of an iced-aircraft envelope, where the limits have to be determined in real time and enforced dynamically. In addition it is preferable to protect against control inputs that will result in envelope exceedence. To accomplish this the method of Horn et al. was applied to icing.

Horn et al. ${ }^{11}$ developed a method for flight envelope cueing and limit prediction for a tilt-rotor aircraft. The formulation was based on the assumption that flight envelope limits are reached during a sustained maneuver. Thus, instead of implementing envelope limits using instantaneous sensor data, a system was developed to predict the future values of critical parameters, at the beginning of a maneuver based on the aircraft state and the control inputs. Envelope violation was predicted by comparison of the estimated limiting values of the critical parameters. If the aircraft state was to exceed any of the boundaries of safe flight in the course of a maneuver the pilot was warned with ample time for corrective actions.

To accomplish envelope protection using the method outlined above, Horn et al $^{11}$ utilized a quasisteady maneuvering state, dynamic trim, that is reached by an aircraft due to a control input. The aircraft state was characterized using state parameters such as velocity, angle of attack, pitch rate etc., and control parameters such as elevator and aileron deflections. The critical parameters and equations of motion were then expressed as functions of the state and control parameters. At the onset of a maneuver, the equations of motion were solved for a future dynamic trim state. The estimated state was then used to calculate the value of the critical parameters at dynamic trim. The limits of the critical parameters were found as functions of control inputs and state parameters using simulations.

In icing conditions the equations of motion and the critical parameters become dependent on icing severity. To tailor the real time prediction method of Horn et al. to icing an icing parameter was defined. Consequently the equations of motion, the critical parameters and the limits of the critical parameters became functions of the icing parameter. Details of the formulation and a discussion of how the limits of the critical parameters can be found as functions of icing severity are given in the following sections.

\subsubsection{Dynamic Trim}

The idea of dynamic trim was introduced as a crucial component to the approach discussed above. A dynamic trim condition was defined as any dynamic flight condition that a pilot is likely to sustain over several seconds in order to maneuver the aircraft. It was assumed that during dynamic trim the time rate of change of the aerodynamic angles and angular accelerations are zero. For a typical aircraft the following conditions will hold during dynamic trim.

$$
\begin{gathered}
\dot{\alpha}=\dot{q}=0 \\
\dot{p}=\dot{r}=\dot{\beta}=0
\end{gathered}
$$

In applying this formulation to icing, one additional assumption needs to be made. For the dynamic envelope it is assumed that during dynamic trim the time derivative of the icing severity parameter, ${ }^{4} \eta_{\text {ice }}$ is zero.

$$
\dot{\eta}_{i c e}=0
$$

\subsubsection{State, Control, Icing and Limit Vectors}

In order to facilitate the determination of the flight envelope limits Horn et al. ${ }^{11}$ introduced a state vector, a control vector, and a limit vector.

The state vector represents the state of the aircraft at time $\mathrm{t}$ in terms of the state variables, the Euler angles, the aerodynamic angles and the angular rates. In addition, the state vector is partitioned into fast states and slow states. The fast states include those that tend to quickly reach a steady value during a normal maneuver. The slow states are those that continue to vary during the maneuver.

In the icing formulation the state vector has been modified to include the pitch attitude: 


$$
\begin{aligned}
\bar{x} & =\left[\begin{array}{llll}
\bar{x}_{\text {slow }} & \bar{x}_{\text {fast }}
\end{array}\right]^{T} \\
\bar{x}_{\text {slow }} & =\left[\begin{array}{lllll}
V & \gamma & \psi & \theta & \phi
\end{array}\right]^{T} \\
\bar{x}_{\text {fast }} & =\left[\begin{array}{lllll}
\alpha & \beta & p & q & r
\end{array}\right]^{T}
\end{aligned}
$$

The control vector includes the control surface deflections and a thrust parameter:

$$
\bar{u}=\left[\begin{array}{llll}
\delta_{e} & \delta_{a} & \delta_{r} & \delta_{\text {power }}
\end{array}\right]^{T}
$$

To account for the change in the aircraft dynamics as a result of icing, an icing parameter vector is defined. The icing parameter vector is formulated such that the effect of icing on the aircraft can be modeled in the equations of motion and the aircraft envelope. Hence, it includes parameters sensitive to icing severity.

$$
\bar{\theta}_{i c e}=\left[\eta_{i c e} \quad \Delta C_{L} \quad \Delta C_{H} \quad \Delta C_{H, R M S} \quad \Delta C_{L \alpha} . . .\right]^{T}
$$

Using the definitions of the state, control and icing parameter vectors, the aircraft equations of motion can be written as:

$$
\dot{\bar{x}}=g\left(\bar{x}, \bar{u}, \bar{\theta}_{i c e}\right)
$$

To complete the formulation the flight envelope is expressed through the envelope parameter vector. The envelope parameter vector consists of the critical parameters that need to be constrained within the safe flight envelope. From the discussion in section 3.1 these include the angle of attack, and the bank angle. However, in the future other parameters such as the load factor may be included in the formulation.

$$
\bar{y}_{p}=\left[\begin{array}{ll}
\alpha & \phi
\end{array}\right]
$$

The envelope parameter vector needs to be defined as a function of the available state, the control and icing vectors. The limits of the envelope parameter vector, the maximum allowable values of the critical parameters at the given icing condition, were defined as functions of the icing parameter vector:

$$
\begin{gathered}
\bar{y}_{p}=\bar{y}_{p}\left(\bar{x}, \bar{u}, \bar{\theta}_{i c e}\right) \\
\bar{y}_{p \lim }=\left[\begin{array}{ll}
\alpha_{\max } & \phi_{\max }
\end{array}\right]^{T} \\
\bar{y}_{p \lim }=\bar{y}_{p \lim }\left(\bar{\theta}_{i c e}\right)
\end{gathered}
$$

\subsection{Limit Boundaries}

The limit boundary is a representation of the envelope parameter limits in control space. In practice the dimension of the control space equals the number of elements in the control vector. Figure 1 is a simplified illustration of the control space where the boundaries are represented as functions of two arbitrary control inputs $u_{i}$ and $u_{j}$.

In Fig. 1 the solid line represents the clean limit and the dotted line represents the iced limit. The arrows from the current control position represent the critical control vectors for limit violation. It must be noted that the critical control inputs are the minimum deflections required to reach the limit boundary from the current control position. As is illustrated in the figure, the critical control vector to the iced boundary is shorter than that for the clean one and hence the iced limit boundary would in general be reached earlier than the clean limit boundary.

\subsection{Determination of the Limit Boundaries}

The limit boundary for a clean aircraft is known or can be found easily. However, in order to determine the limits for flight in icing conditions the functional dependence of the limit boundaries on the icing parameter vector needs to be determined. Unfortunately, insufficient iced aircraft data are available to develop this relationship. Hence, 2D airfoil data for different ice shapes were analyzed. The results of this analysis are shown in Figs. 2 - 4.

Figure 2 is a plot of the change in $C_{L \max }$ due to leading edge ice shapes ${ }^{12}$ placed at various chord locations. $\mathrm{C}_{\mathrm{Lmax}}$ was plotted against $\Delta \mathrm{C}_{\mathrm{L}}$ at a low angle of attack of $4^{\circ} . \Delta \mathrm{C}_{\mathrm{L}}$ is the difference between the lift generated by an airfoil with simulated ice and the clean airfoil at the specified angle of attack $\left(4^{\circ}\right.$ in this case).

$$
\Delta C_{L}=C_{L, \text { iced }\left(\alpha=4^{\circ}\right)}-C_{L, \text { clean }\left(\alpha=4^{\circ}\right)}
$$

It is evident from the figure that there is an almost linear relationship between the $\mathrm{C}_{\mathrm{L}, \max }$ and $\Delta \mathrm{C}_{\mathrm{L}}$. Figure 2 thus illustrates the possibility of successfully predicting stall in icing conditions from the reduction in lift at low angles of attack.

Another example of the dependence of stall on icing parameters is shown in Fig. 3. This is a plot of the increment in angle of attack of an iced airfoil, as compared to the clean airfoil, for a lift coefficient of 0.35 .

$$
\Delta \alpha=\alpha_{\text {iced }\left(C_{L}=0.35\right)}-\alpha_{\text {clean }\left(C_{L}=0.35\right)}
$$


The increment in the angle of attack varied almost linearly with the maximum lift coefficient. However, it must be noted that $\Delta \alpha$ ranges from -0.05 to 0.05 . In flight, identification of such small changes in angle of attack would be very difficult. Hence, although the trend is promising this relationship may not be very helpful in limit prediction.

Figure 4 demonstrates the relationship between the maximum lift coefficients with the change in drag due to icing. The drag corresponded to a lift coefficient of 0.2 .

$$
\Delta C_{D}=C_{D, i \operatorname{ced}\left(C_{L}=0.2\right)}-C_{D, \operatorname{clean}\left(C_{L}=0.2\right)}
$$

This figure indicates that there is a detectable drag rise even when the aircraft is producing low lift. The almost linear relationship between this drag rise and the maximum lift coefficient shows potential for use in stall prediction. Previous flight test data were also analyzed to determine the dependence of aerodynamic parameters on icing. It should be noted that for an airfoil there is no drag due to non-lifting surfaces and that the lift-drag relationship is strong. Figure 5 is a plot of $\mathrm{C}_{\mathrm{D} 0}$ as a function of $\eta_{\text {ice. }}$. The zero-lift drag coefficient was interpolated from Twin Otter icing flight test data published by Mikkelson et al. ${ }^{13}$ and Ranaudo et al. ${ }^{14}$ This plot shows an almost linear correlation between the icing parameter $\eta_{\text {ice }}$ and the zero-lift drag coefficient. Unfortunately no $\mathrm{C}_{\mathrm{L}, \max }$ data were available, but the trend with $\eta_{\text {ice }}$ suggests a relationship with $\mathrm{C}_{\mathrm{L}, \max }$.

\subsection{Steady and Unsteady Hinge Moments}

Trends in the steady and unsteady hinge moments have been identified as potential indicators of icing related performance degradation. ${ }^{15}$ Gurbacki's results on the NACA 23012 airfoil supported the possibility of using the unsteady flap hinge moment as a sensor of ice induced aircraft control problems. ${ }^{15}$ As shown in Fig. 6 the unsteady hinge moment for an airfoil with simulated ice departs drastically from that of the clean curve during the linear phase of the lift curve several degrees before stall. Gurbacki tabulated typical values of angle of attack for breaks in the unsteady and steady hinge moments and stall and discussed the criteria for establishing the breaks. Gurbacki's results for increasing angle of attack also showed that although the break in the steady hinge moments occurred during the nonlinear phase of the lift curve, it provided some warning of stall.

In order to confirm the trends observed by Gurbacki, experiments were recently conducted at the University of Illinois, using the NLF 0414 airfoil. Three geometrically similar simulated glaze horn ice shapes $^{16}$ with leading-edge radius of $25 \%$ of the base width were used for the experiment. The ice shapes were placed at $\mathrm{s} / \mathrm{c}$ locations of $0 \%, 0.85 \%$ and $1.7 \%$ from the leading edge on the upper surface of the airfoil. The experiments were conducted at a Reynolds number of $1.8 \times 10^{6}$.

The results of these experiments indicated that the steady and unsteady hinge moments were quite sensitive to the size and location of the ice shapes. It was found that when the ice shapes were placed at the leading edge there was a maximum warning of impending stall of 1 degree. At s/c locations of $0.85 \%$ and $1.7 \%$, the warnings ranged from 1 to 4 degrees. This trend is illustrated in Fig. 7. In this figure the unsteady hinge moments were plotted for the clean case and with simulated ice shapes at $\mathrm{s} / \mathrm{c}$ locations of $0 \%$ and $0.85 \%$. It is evident from this plot that the break in the hinge moment occurs earlier if the ice shape is moved aft. Note that the $\mathrm{C}_{\mathrm{h}, \mathrm{RMS}}$ at $\alpha_{\text {stall }}$ is indicated on the plots.

Increasing the size of the ice shape also resulted in an earlier warning for stall. This is illustrated in

Fig. 8 where as the $\mathrm{k} / \mathrm{c}$ values of the ice shapes increase the unsteady hinge moment breaks away from the clean curve at lower angles of attack.

The values of the angle of attack for the $C_{h, R M S}$ break and stall for a flap deflection of 0 degrees are shown in Table 1. Following Gurbacki ${ }^{15}$ the $\mathrm{C}_{\mathrm{h}, \mathrm{RMS}}$ break was defined as the angle of attack at which the ratio of the iced $\mathrm{C}_{\mathrm{h}, \mathrm{RMS}}$ to the clean $\mathrm{C}_{\mathrm{h}, \mathrm{RMS}}$ was greater that 1.20. It is evident that the break in the $\mathrm{C}_{\mathrm{h}, \mathrm{RMS}}$ for the NLF 0414 occurred, in general, closer to stall than for the NACA 23012 tested by Gurbacki. This may be due to the different stall characteristics of the two airfoils or the different ice shapes. However, these results further enforce the possibility of using flap hinge-moment sensors for envelope protection.

The break in the steady hinge moments also occurred before stall. As shown in Figs. 9 and 10 the advent of the non-linear region is much more pronounced than that for the clean case. Also, the point at which the non-linear region begins occurs at lower angles of attack for ice shapes of higher $\mathrm{k} / \mathrm{c}$ values. This may be attributed to the larger separation bubbles caused by the larger ice shapes thus reducing the pressure and causing an abrupt decrease in the hinge moments. Similarly, as the ice shapes were moved further aft the breaks occurred at lower angles of attack. However, it must be noted that the change in hinge moment due to the ice shapes is not as distinct on the NLF 0414 airfoil as it was with the NACA 23012. ${ }^{15}$ This may be due to the greater inherent adverse pressure gradient toward the trailing edge of the NLF 0414 airfoil. 


\section{ATMOSPHERIC DISTURBANCES}

Aircraft icing is assumed to have a unique effect on the performance, stability and control of an aircraft. Atmospheric disturbances could produce similar changes in aircraft performance and control under some situations. It is important to show that these effects can be distinguished from aircraft icing. Both gravity waves and microbursts are studied in this paper to determine their ability to generate ice-like results. In addition to the microbursts and gravity waves, the current random atmospheric disturbance generators in FDC are reexamined in this study.

\subsection{Wind Effects Implementation}

Implementing these events was quite simple in the FDC. The FDC already had a wind shear model incorporated in the program. This model computes the horizontal components of the wind shear. It then implements the effect of the wind by adding an effective wind component of force along the body fixed axes which then become:

$$
\begin{aligned}
& F_{x}=X_{\text {aerodynami }}+X_{\text {propulsion }}+X_{\text {gravity }}+X_{\text {wind }} \\
& F_{y}=Y_{\text {aerodynami }}+Y_{\text {propulsion }}+Y_{\text {gravity }}+Y_{\text {wind }} \\
& F_{z}=Z_{\text {aerodynami }}+Z_{\text {propulsion }}+Z_{\text {gravity }}+Z_{\text {wind }}
\end{aligned}
$$

where the force components due to the wind are:

$$
\begin{gathered}
X_{x}=-m\left(\dot{u}_{w}+q w_{w}-r v_{w}\right) \\
Y_{w}=-m\left(\dot{v}_{w}-p w_{w}+r u_{w}\right) \\
z_{w}=-m\left(\dot{w}_{w}+p v_{w}-p u_{w}\right)
\end{gathered}
$$

When the turbulence increases and large wind gradients occur, the wind can create simulated rotation rates on the aircraft. The longitudinal rate, here the pitch, was considered when analyzing microbursts and gravity waves.

The gradient effect of the wind in the longitudinal direction was modeled using the following equation ${ }^{17}$

$$
q_{\text {new }}=q-q_{g}
$$

where

$$
q_{g}=-\frac{\partial w_{w}}{\partial x}
$$

The spatial derivative was computed from the time derivative using the Taylor Hypothesis. Taylor's Hypothesis was modified from its typical form to become $^{18}$

$$
\frac{\partial w_{w}}{\partial x}=\frac{1}{\bar{V}} \frac{\partial w_{w}}{\partial t}
$$

By combining Etkin's formula and Taylor's Hypothesis, the effective wind pitch rate was determined using

$$
q_{g}=-\frac{1}{\bar{V}} \frac{\partial w_{w}}{\partial t}
$$

This new pitch rate was then implemented in FDC.

\subsection{Microburst Model}

Microbursts are a well known atmospheric phenomenon that degrade aircraft performance and pose a serious safety problem. Microbursts occur close to the ground and are encountered during landing and takeoff. In terms of the aircraft, the phenomenon is seen initially as a headwind, then as a downdraft and finally as a tailwind, as shown in Fig. $11 .^{5}$ When the aircraft first encounters the headwind it will see an increase in performance. In order to prevent a climb, the pilot must take action such as reducing power. As the aircraft passes into the downdraft and the tailwind, the performance of the aircraft quickly decreases, and could even lead to a loss in control (i.e. stall).

A microburst model developed by NASA in $1988^{6}$ was used for this analysis. The velocities for the horizontal and vertical directions were approximated by the following equations:

$$
\begin{gathered}
u=\frac{\lambda R^{2}}{2 r}\left[1-e^{-(r / R)^{2}}\right]\left(e^{-z / z^{*}}-e^{-z / \varepsilon}\right) \\
w=-\lambda e^{-(r / R)^{2}}\left[\varepsilon\left(e^{-z / \varepsilon}-1\right)-z *\left(e^{-z / z^{*}}-1\right)\right]
\end{gathered}
$$

\subsection{Gravity Wave Model}

Unlike microbursts, gravity waves are not a wellunderstood phenomenon. Gravity (buoyancy) waves in the atmosphere are very similar to surface waves on water. The density discontinuity between the layers causes the air to sink or rise due to the restoring force of gravity. Although these types of waves can be caused in a variety of ways, the most common cause is flow over mountains, which are also known as mountain waves. ${ }^{19}$ Mountains cause gravity waves by 
displacing the air as it flows over the peak of the mountain.

A useful way to visualize these waves is to consider a corrugated sheet moving through a fluid, Fig. 12. The displacement of the air will follow the geometry of the corrugations. The maximum displacement of air will move along the line attached to the high point of the corrugations, shown upwards and sloping to the right. As the air rises it will cool due to adiabatic cooling and this region will be the coolest. The minimum air displacements follow the low points in the corrugations shown by the lines from the troughs of the corrugations. As these parcels of air move downward they will be heated by adiabatic processes and will be the warmest region. Up to this point gravity waves have been described in the reference frame of the air. In the reference frame of the corrugations the waves appear to be stationary. This is exactly why Lee-waves over mountains appear to be stationary. ${ }^{7}$

With this basic understanding of gravity waves it is now possible to determine the relationship of the vertical displacement, wind velocities, pressure, temperature, and density to the geometry of the wave. If a slice is taken through the wave at a certain level it is possible to see the variations in the above parameters, seen as slice D in Fig. 12. Figure 13 presents the variation of all these parameters. As the vertical displacement of the wave approaches a maximum the density approaches a maximum while the temperature approaches a minimum. The pressure and velocity are both increasing, but are out of phase from the displacement by 90 degrees. ${ }^{7}$

The amplitude and wavelengths of these waves can vary greatly depending on the type of wave, and the altitude of the wave. The amplitude of these waves increase as the altitude increases. In the troposphere, the velocity amplitude is typically in the range of a few centimeters per second, while in the mesosphere the amplitudes can be in the range of meters per second. ${ }^{6}$ Similar to the amplitude, the period/wavelength of the waves varies greatly. Typical wavelengths vary from one kilometer to several hundred kilometers. Therefore, the intensity of the wave can also vary greatly. A short wavelength with large amplitude will have a greater effect on an aircraft than a long wavelength with a small amplitude.

Gravity wave implementation was similar to the microburst implementation. A sine wave was used to generate the vertical wind velocity $v_{w}$, where the amplitude and the period of the wave could be controlled. Variations in the other velocity components, temperature, density, and pressure were assumed to have small effect on the aircraft and ignored. A large range of wavelengths and amplitudes were examined in this study. Although the smaller gravity waves are more likely to simulate icing, it was important to cover the entire range to determine a good generalization of the effect of these waves. Wavelengths from 1 to 64 kilometers and velocity amplitudes from 0 to $2 \mathrm{~m} / \mathrm{s}$ were studied, Table 2 .

\subsection{Microburst Validation}

The validation of the wind model in FDC was accomplished by comparison to the published results ${ }^{18}$ of the response of the Cessna $402 \mathrm{~B}^{20}$ aircraft to a wind shear encounter. Figure 14 presents the angle of attack profiles for both the current results and those of Ref. 6 . There are slight differences between the two profiles, which can be explained.

The published simulations were conducted during a descent, holding the flight path to a specified glideslope angle and adjusting the throttle to compensate. The FDC simulations were conducted using an altitude hold that adjusted the angle of attack. This difference explains the initial drop in the FDC angle of attack. The throttle lag and the pitch rate limiter used in the published data account for the other differences. Although the profiles do not match perfectly, the differences are a result of the differences in aircraft flight profiles. Therefore, the results suggest that the wind model was implemented correctly into FDC.

\subsection{Results}

\subsubsection{Pitch Rate Term Effect}

Although the gradients of the microbursts and gravity waves were very large, the effect of the pitch rate term was minimal when using the closed loop autopilot analysis. The conditions for this analysis were:

- Velocity $136 \mathrm{kts}$.

- $\quad$ Altitude $1640 \mathrm{ft}$

- Trimmed flight

- Altitude hold autopilot setting and no autopilot Setting

- Constant power

- Microburst \#5 simulation run

- $\quad$ Radius $=3000 \mathrm{ft}$

- $\quad$ Umax $=10 \mathrm{ft} / \mathrm{s}$

The angle of attack profile for both the autopilot-on and autopilot-off cases were presented in Fig. 15 with the autopilot-on case in Fig. 15a and the autopilot off case in Fig. 15b. It can be seen that the angle of attack profiles are virtually identical for both cases with autopilot-on in Fig. 15a. 
When the autopilot was disconnected and no longer attempting to maintain the altitude, the results are much different, Fig. 15b. The pitch rate term has an important effect on the performance of the aircraft through the microburst when the altitude was not maintained. The alpha profile, Fig. 15b, differs significantly from the closed loop simulation at all with the angles of attack oscillating but remaining close to $0.42^{\circ}$. The profile without the $\mathrm{q}_{\mathrm{g}}$ term has a slow decrease in alpha initially as the aircraft enters the microburst. The profile then begins to oscillate and eventually damps out after the aircraft exits the microburst. The profile with the $\mathrm{q}_{\mathrm{g}}$ term also oscillates about $0.42^{\circ}$ with the oscillations more pronounced as the aircraft enters the microburst and more damped as the aircraft exits.

The most important result of this analysis was that the gust pitch rate term was important when analyzing the open-loop simulation. However, the autopilot was able to compensate for the gust pitch rate in the altitude-hold mode. Therefore, the simulations showed that with the autopilot engaged the gust-pitchrate term did not significantly affect the flight parameters and as a result could be ignored. A more detailed description of the autopilot is available in Ref. 21.

\subsubsection{Microburst Results}

In order to determine the effects of microbursts and gravity waves, a variety of sizes and strengths of encounters have been examined. Microbursts and gravity waves of different strengths and sizes were easily simulated using the models described in Sections 3.2 and 3.3.

Microbursts can be differentiated quickly and easily as seen in Refs. 4 and 22. The changes in velocity, angle of attack and elevator deflection were considerably different for icing and microbursts. Even the small microbursts have quick abrupt changes in the parameters. In addition, the autopilot was able to maintain altitude during the icing encounters while it was not able to do so during the microbursts. Lastly, since microbursts and icing are typically exclusive phenomenon it would be very unlikely that the need to distinguish between the two will ever arise. A more detailed analysis on the effect of microbursts can be found in Refs 4 and 22.

\subsubsection{Gravity Wave Results}

For the gravity wave analysis the aircraft initial state was held constant, while the gravity wave amplitude and period were varied. The initial state for the Twin Otter was
- Velocity $136 \mathrm{kts}$

- Altitude $7540 \mathrm{ft}$

- Trimmed flight

- Altitude hold autopilot setting

- Constant power

- $\eta=0.0$ for the non-icing cases and $\eta=0.08$ for the icing case

- Initial gravity wave wind velocity of $0 \mathrm{~m} / \mathrm{s}$

The simulation was initialized with the above parameters with zero icing and a zero value for the gravity wave wind velocity. Once the simulation was begun the icing started and the gravity wave wind velocity began to vary along the periodic shape. For the icing cases $\eta=0.0$ at $\mathrm{t}=0$ and increased linearly until $\eta=0.08$ at $\mathrm{t}=600$ seconds simulating an icing encounter.

Before the effect of the gravity wave parameters was examined, it was important to examine the phase relationship of the different performance parameters. Figure 16 presents the z-wind velocity, aircraft angle of attack, and the aircraft velocity for a gravity wave. It was clear that the angle of attack lagged the change in wind velocity significantly. This was mainly a result of the lag from the constant altitude hold autopilot setting. The aircraft velocity also lagged the z-wind velocity, but slightly led the angle of attack. Although these phase relationships were a result of the autopilot, the response of the angle of attack and velocity were not overly affected by the lag and were still a result of the changing wind velocity.

The increasing wavelength has a very unique and interesting effect on the angle of attack of the aircraft. Initially the wavelength was so short and the period was so small that the aircraft had very little time to react, as seen in Fig. 17. The period was so small that the angle of attack does not change substantially and was filtered out. Therefore the very small wavelengths were very similar to random turbulence that will be discussed in the next section. More interesting was that as the wavelength increased the maximum angle of attack change increased. The main reason for this effect is that the aircraft had a greater amount of time to react to the change and therefore the autopilot was able to change the angle of attack to maintain the altitude.

The effect on velocity was also evident as shown in Fig. 18. The effect of the smaller wavelengths was a little more clear when examining the velocity, although the overall effect was certainly minimal. As before, there was a big jump in the effect of wavelength. The maximum change in velocity also increased as the wavelength increased. The major difference between the angle of attack and the velocity was that the time of the maximums was slightly 
different. For a given wavelength the angle of attack maximum lagged slightly behind the maximum for the aircraft velocity. The cause of the increasing maximum change in alpha was the aircraft experienced the larger winds for a much longer time with the increased wavelengths. This increased time and then required more input to maintain altitude and therefore causes larger changes in the aircraft state.

Figure 19a demonstrates that as the $\mathrm{z}$ wind velocity increases the angle of attack increases were as expected. The peak angle of attack slightly lagged the peak in $\mathrm{Z}$ wind velocity. A small change in wave amplitude had a large effect on the change in angle of attack. The increase in wave amplitude from $1.0 \mathrm{~m} / \mathrm{s}$ to $2.0 \mathrm{~m} / \mathrm{s}$ caused the maximum change in angle of attack to increase from $0.7^{0}$ to $1.7^{0}$. If the initialization of the wave was reversed, the effect of the angle of attack was similar with the response of the angle of attack is reversed, Fig. 19b. The first decrease in angle of attack was stretched in time in comparison to the other peaks due to the response of the aircraft to the initial change wind velocity.

Another result of the increasing amplitude was that the angle of attack response became more asymmetric. The increase in angle of attack no longer equaled the decrease in angle of attack. This was a direct result of the nature of the wind. Initially the aircraft response to a downdraft was a translation in altitude. Therefore altitude was lost and the autopilot responded and attempted to gain altitude. As the aircraft continued to fly in the wave the translation was followed by an effective loss in angle of attack, caused the autopilot to increase the angle of attack even more. The opposite effect happened during the updraft. The effective angle of attack increased and the updraft translated the aircraft upward increasing the altitude, therefore the angle of attack was much lower during the updrafts. The corresponding velocity results can be seen in Fig. 20.

Unlike microbursts, gravity waves and icing were much more likely to occur simultaneously and had similar effects on the aircraft. Therefore a more in depth comparison of icing and gravity waves was necessary. Figures 21 and 22 present the aircraft parameters for small gravity waves and icing levels. A small gravity wave was used since it's effect will model the icing effect much more closely than the larger gravity waves which will simulate a response closer to a microburst. Icing of $\eta=0.00$ and 0.08 were compared to gravity waves of period 229 seconds and an amplitude of $0.5 \mathrm{~m} / \mathrm{s}$. In addition, gravity waves starting with both positive and negative wind velocity slopes were analyzed.

Angle of attack provided the greatest clue into the phenomenon of icing and gravity waves. Fig. 21a demonstrated that the gravity waves effect will combine with the icing effects, but the overall trend will follow the non-periodic icing. This would also be true even with the larger gravity waves. If the gravity wave was reversed the effect is the same, but is 180 degrees out of phase. Therefore the effects from both gravity waves surround the icing effects.

More importantly was the initial onset of the phenomenon. Figure 21a was a magnification of Fig. $21 \mathrm{~b}$ near the onset of the cases. For the first 50 seconds very little happened to the state of the aircraft. After the first 40-50 seconds the phenomenon began to change the state of the aircraft. Looking at Fig. $21 \mathrm{~b}$ it would appear that the three lines that increase the angle of attack would all be icing cases. Unfortunately, that was not the case. In fact, the second highest increase in angle of attack (dashed) line had no icing at all, it is the case with the positive gravity wave and no icing. The solid black line was the pure icing case and it's initial onset is the least serious of all the cases. The two cases that decrease initially were also very important. The negative initialization with icing line has both the icing and gravity wave effects, but it appears that the aircraft performance is increasing. The concern with this case is that the gravity wave could possibly mask the effect of the icing. This type of problem would then be compounded when the gravity wave effect reversed and added to the icing. Again the velocity results corresponded to the angle of attack results, Fig. 22.

Based on these results it was apparent that gravity waves present more of a challenge when compared to icing effects. The effects of ice and gravity waves were very similar during the initial onset of each disturbance. It was clear that icing and gravity waves were distinguishable once the amount of ice accretion has become large. The ice detection/characterization system will have to be more sophisticated to distinguish icing effects from gravity waves.

\subsubsection{Atmospheric Turbulence changes and effects}

The Twin Otter Model was at the following initial state for the atmospheric turbulence study.

- Velocity $136 \mathrm{kts}$

- Altitude $7540 \mathrm{ft}$

- Trimmed flight

- Altitude hold autopilot setting

- Constant power

- $\eta=0.0$ for all cases

The initial application of the turbulence model in FDC focused on varying the scale length of the turbulence not the intensity. By varying the scale length the aircraft $z$-acceleration changes, but a considerable amount of information about the turbulence is lost using this parameter. Therefore it 
was important to study the effect of scale length and the turbulence intensity (turbulence velocity RMS).

NASA Handbook 1001 "Terrestrial Environment (climatic) Criteria Handbook for use in Aerospace" presents standards for the Dryden filters. ${ }^{23}$ In addition it states that the scale length of the turbulence is constant for a constant altitude. Therefore the scale length no longer has to be changed as long as the altitude is fairly constant for the simulations. Table 3 presents the data for an altitude of $2000 \mathrm{~m}$ and the corresponding scale lengths, turbulence velocity RMS values, and the corresponding aircraft z-acceleration from FDC for the aircraft state listed above. Three different types of turbulence are presented, light, moderate, and severe. The resulting z-acceleration RMS values then range from $0.007 \mathrm{~g}$ to $0.245 \mathrm{~g}$.

It is interesting to look at constant values of the turbulence intensity. Here are 4 combinations of scale length and turbulence velocity RMS that result in $0.15 \mathrm{~g}$ z-acceleration RMS. The larger scale length represent values of $500 \mathrm{~m}$ and $1000 \mathrm{~m}$ that correspond to the data obtained from the NASA handbook.

- $\quad$ Scale Length $(\mathrm{L})=23 \mathrm{~m}$, Turbulence Velocity $\operatorname{RMS}(\sigma)=0.498 \mathrm{~m} / \mathrm{s}$

- $\quad$ Scale Length (L) $=92 \mathrm{~m}$, Turbulence Velocity $\operatorname{RMS}(\sigma)=0.992 \mathrm{~m} / \mathrm{s}$

- $\quad$ Scale Length $(\mathrm{L})=500 \mathrm{~m}$, Turbulence Velocity $\operatorname{RMS}(\sigma)=2.37 \mathrm{~m} / \mathrm{s}$

- $\quad$ Scale Length (L) $=1000 \mathrm{~m}$, Turbulence Velocity $\operatorname{RMS}(\sigma)=3.29 \mathrm{~m} / \mathrm{s}$

For easy comparison the turbulence profile was held constant. Figures 23-25 present the z-acceleration, angle of attack, velocity, and altitude for the 4 combinations of scale length and turbulence velocity RMS.

Figure 23 is very important because it demonstrates that a considerable amount of dynamic response is missing for the smaller scale lengths. With the smaller scale lengths the variation of the angle of attack is very small. As the scale length increases so does the turbulence velocity RMS and therefore the excitation of the angle of attack increases considerably. Figures 24 and 25 correspond directly and demonstrate that the amount of information and excitation increases considerably for the larger scale lengths.

The more realistic turbulence simulations provided by the larger turbulence scale lengths are important in the development of icing characterization methods using system identifications techniques. As shown in Figs. 23 and 24 the larger scale lengths result in much richer dynamic input to the aircraft which will aid identification. It may be possible to identify changes due to icing without control inputs (doublets) if sufficient turbulence in present to excite the aircraft dynamics.

\section{CONCLUSIONS}

The following conclusions can be made based upon this research:

- The gust pitch rate term is negligible with the autopilot operating and therefore can be eliminated to save computational time.

- Small gravity waves have similar performance effects as ice accretion. More research is needed on this topic.

- The manner in which the phenomenon affect the aircraft and control surface effectiveness will play role in distinguishing gravity waves from icing.

- A considerable amount of dynamics information can potentially be gained using the larger scale lengths that will help system identification modeling and performance.

- The idea of a dynamic envelope is essential for envelope protection under icing conditions to account for the shrinking of the safe flight boundaries with ice accretion.

- Two dimensional airfoil data showed promising results for guiding prediction of limit exceedence.

- $\quad$ Steady and unsteady hinge moments provide stall warning.

\section{ACKNOWLEDGEMENTS}

This work was supported by a NASA Glenn grant NAG 3-21235. The authors would like to thank Mr. Tom Bond, Mr. Tom Ratvasky and Dr. Mark Potapczuk of NASA Glenn for their contributions. Several members of the Smart Icing Systems research group at Illinois contributed to this research including, Dr. Sam Lee, Mr. Ramesh Arakoni and Ms. Leia Blumenthal and many others.

\section{REFERENCES}

${ }^{1}$ Bragg, M.B., Perkins, W.R., Sarter N.B., Basar, T., Voulgaris, P.G., Gurbacki, H.M., Melody, J.W. and McCray, S.A., "An Interdisciplinary Approach to Inflight Aircraft Icing Safety," AIAA Paper No. 980095, Reno, NV, January 12-15, 1998.

${ }^{2}$ Bragg, M. B., Perkins, W.R., Basar, T., Sarter, N. B., Voulgaris, P. G., Selig, M., and Melody, J., " Smart Icing Systems for Aircraft Icing Safety," AIAA Paper No. 2002-0813, Reno, NV, Jan., 2002. 
${ }^{3}$ Bragg, M.B., Hutchison, T., Merret, J., Oltman, R., and Pokhariyal, D., "Effects of Ice Accretion on Aircraft Flight Dynamics," AIAA Paper No. 20000360, Reno, NV, Jan. 2000.

${ }^{4}$ Pokhariyal D., Bragg M. B., Hutchison, T., Merret, J., "Aircraft Flight Dynamics with Simulated Ice Accretion" AIAA Paper No, 2001-0541, Reno, NV, Jan.2001.

5 Mulgund, S.S., and Stengel, R.F., "Target Pitch Angle for the Microburst Escape Maneuver, " Journal of Aircraft, Vol. 30, No. 6, Nov.-Dec. 1993.

6 Oseguera, R.M., and Bowles, R.L., "A simple Analytical 3-Dimensional Downburst Model Based on Boundary Layer Stagnation Flow," NASA TM 1000632.

${ }^{7}$ W Hocking Class Notes, Physics 103, University of Western Ontario, http://quark.physics.uwo.ca / whoc king/p103/grav wav.html, 5/3/01.

${ }^{8}$ Gedzelman, Stanley D., The Science and Wonders of the Atmosphere, John Wiley and Sons, New York, 1980 .

9 North, M. D., "Finding Common Ground IN Envelope Protection Systems," Aviation Week \& Space Technology, August 28, 2000.

10 National Transportation Safety Board, "Aircraft Accident Report: Inflight Icing Encounter and Loss of Control Simmons Airlines, d.b.a. American Eagle Flight 4184 Avions de Transport Regional (ATR) Model 72-2122, N401AM, Roselawn, Indiana, October 31, 1994," Safety Board Report, NTSB/AAR96/01, PB96-910401, Volume 1, July 1996.

11 Horn, J., Calise, A. J., Prasad, J. V. R., and O'Rourke, M., "Flight Envelope Cueing on a TiltRotor Aircraft Using Neural Network Limit Prediction," AHS 54 ${ }^{\text {th }}$ Forum, 1998.

${ }^{12}$ Kim, H. S., and Bragg, M. B., "Effects of Leading Edge Ice Accretion Geometry on Airfoil Aerodynamics," AIAA paper 99-3150, Norfolk, VA, July 1999.

${ }^{13}$ Mikkelsen, K. L., McKnight, R. C., and Ranaudo, R. J., "Icing Flight Research: Aerodynamic Effects of Ice and Ice Shape Documentation With Stereo Phtography," AIAA paper 85-0468 also NASA/TM 86906, Reno, NV, Jan., 1985.
${ }^{14}$ Ranaudo, R. J., Mikkelsen, K. L., McKnight, R. C., Ide, R. F., Reehorst, A. L., Jordan, J. L., Schinstock, W. C., and Platz, S. J., "The Measurement of Aircraft Performance and Stability and Control After Flight Through Natural Icing Conditions," AIAA paper 869758 also NASA/TM 87265, Las Vegas, NV, April 1986.

15 Gurbacki, M. H. and Bragg, M. B., "Sensing Aircraft Icing Effects by Flap Hinge Moment Measurement," AIAA Paper No. 99-3149, Norfolk VA, June 1999.

${ }^{16} \mathrm{Kim}, \mathrm{H}$. S. and Bragg M. B., "Effets of Leading Edge Ice Accretion Geometry on Airfoil Performance," AIAA paper

17 Etkin, B. and Etkin, D., "Critical Aspects of Trajectory Prediction: Flight in Non-Uniform Wind," AGARDograph No. 301, v. 1 (1990).

${ }^{18}$ Bruun, H. H., Hot Wire Anemometry: Principle and Signal Analysis, Oxford University Press, New York, 1995.

${ }^{19}$ Gedzelman, Stanley D., The Science and Wonders of the Atmosphere, John Wiley and Sons, New York, 1980.

${ }^{20}$ Hoh, R., Mitchell, D., and Meyer, T., "Simulation Model of Cessna 402B," NASA Ames Research Center, NASA CR152176, Moffett Field, CA, July 1978.

${ }^{21}$ Sharma, V. and Voulgaris, P., "Effects of Icing on the Autopilot Performance," AIAA Paper No. 20020815, Reno, NV, Jan. 2002.

${ }^{22}$ Merret, Jason, "Effect of Atmospheric Disturbances in Conjunction with Aircraft Icing on Aircraft Performance and Control During Trimmed Flight," M.S. Thesis, University of Illinois, Urbana, IL, Dec 2001.

23 "Terrestrial Environment (climatic) Criteria Handbook for use in Aerospace", NASA Handbook1001, http://standards.nasa.gov/ RELEASED/1001 /1001.htm. 
Table 1. Comparison of the stall angle of attack with the break in $\mathrm{C}_{\mathrm{h}, \mathrm{RMS}}$

\begin{tabular}{|c|c|c|c|c|}
\hline $\mathrm{s} / \mathrm{c}(\%)$ & $\mathrm{k} / \mathrm{c}(\%)$ & $\mathrm{C}_{\mathrm{h}, \mathrm{RMS}}$ Break (deg) & $\alpha_{\text {stall }}(\mathrm{deg})$ & Warning (deg) \\
\hline 0.85 & 2 & 6.1535 & 7.385 & 1.2315 \\
\hline 1.7 & 2 & 3.7893 & 5.945 & 2.1557 \\
\hline 0 & 4.33 & 8.261 & 8.835 & 0.574 \\
\hline 0.85 & 4.33 & 4.7036 & 6.615 & 1.9114 \\
\hline 1.7 & 4.33 & 2.0951 & 4.8 & 2.7049 \\
\hline 0 & 6.67 & 7.6536 & 8.705 & 1.0514 \\
\hline 0.85 & 6.67 & 2.5 & 5.61 & 3.11 \\
\hline 1.7 & 6.67 & -0.5341 & 3.5 & 4.0341 \\
\hline
\end{tabular}

Table 2. Gravity Wave Parameters

\begin{tabular}{|c|c|}
\hline Velocity Amplitudes (m/s) & Wavelengths $(\mathrm{km})$ \\
\hline 0 & 1 \\
\hline 0.5 & 2 \\
\hline 1 & 8 \\
\hline 2 & 16 \\
\hline & 32 \\
\hline & 64 \\
\cline { 2 - 2 }
\end{tabular}

Table 3. NASA Dryden Filter Standards ${ }^{4}$

\begin{tabular}{|c|c|c|c|}
\hline Trubulence Type & Light & Moderate & Severe \\
\hline Horizontal Ref. Length $(\mathrm{m})$ & 902 & 902 & 902 \\
\hline Vertical Ref. Length $(\mathrm{m})$ & 831 & 831 & 831 \\
\hline Horizontal Vel. RMS (m/s) & 0.17 & 1.65 & 5.8 \\
\hline Vertical Vel. RMS (m/s) & 0.14 & 1.43 & 4.75 \\
\hline $\begin{array}{c}\text { Present aircraft z- } \\
\text { acceleration RMS results } \\
\left(\mathrm{m} / \mathrm{s}^{2}\right)\end{array}$ & 0.007 & 0.073 & 0.245 \\
\hline
\end{tabular}

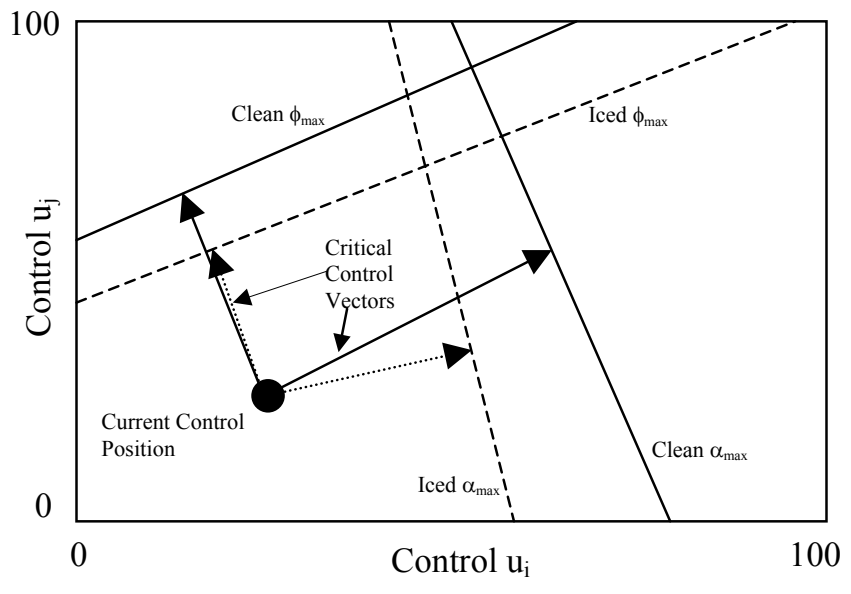

Fig. 1. Limit Boundaries where $u_{i}$ and $u_{j}$ are arbitrary control inputs.

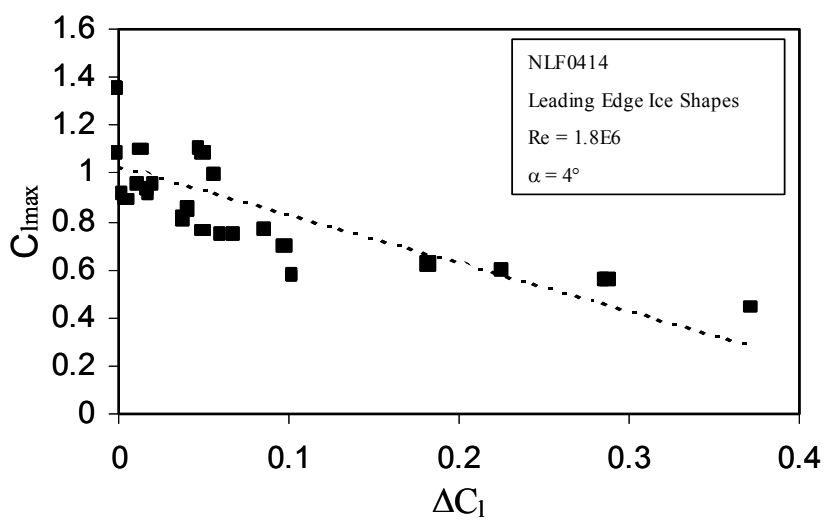

Fig. 2. Variation in Maximum Lift with Change in Lift at Fixed Angle of Attack

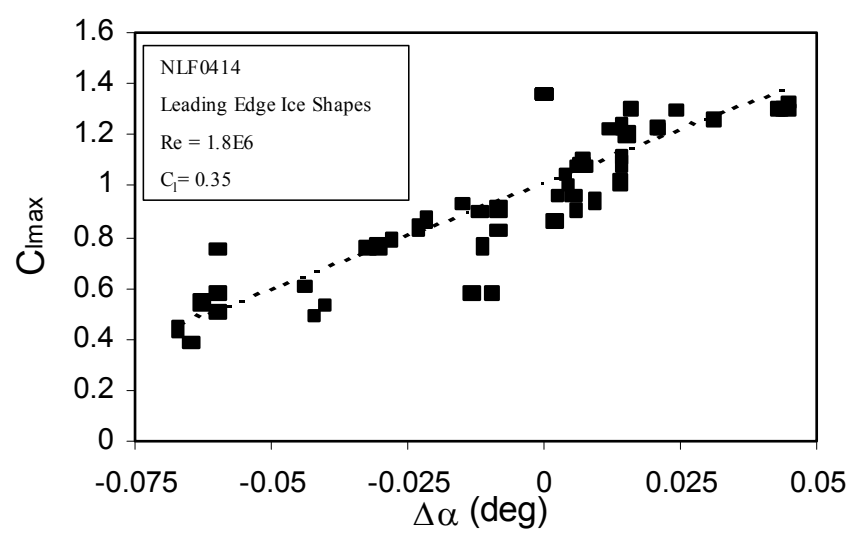

Fig. 3. Comparison of Maximum Lift Coefficient with the change in required angle of attack for Fixed Lift Coefficient

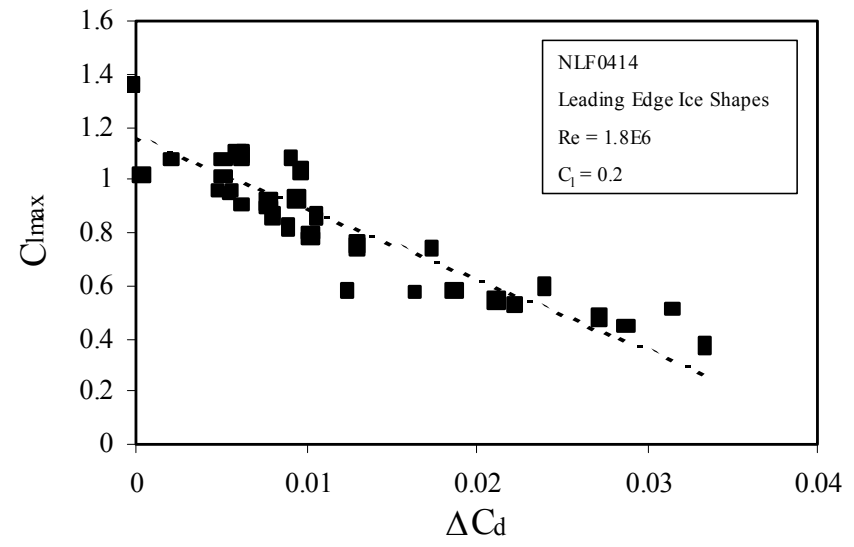

Fig. 4. Variation of Maximum Lift Coefficient with Drag Rise 


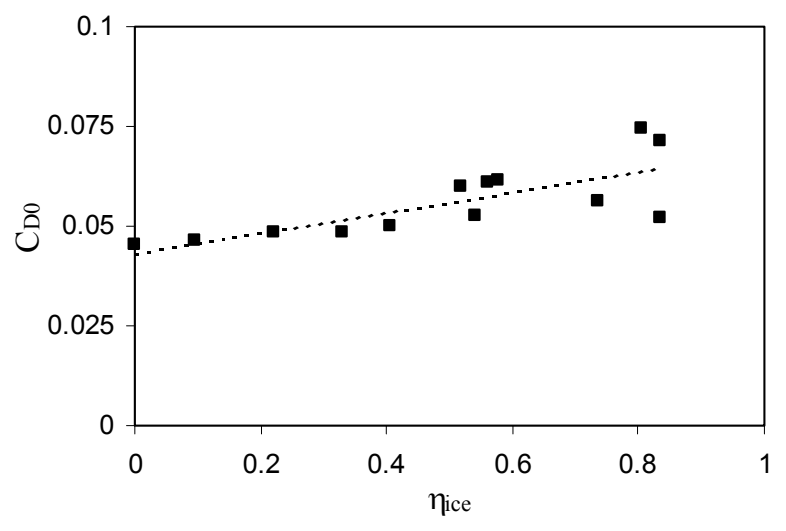

Fig. 5. Comparison of Zero Lift Drag Coefficient with $\eta_{\text {ice }}$

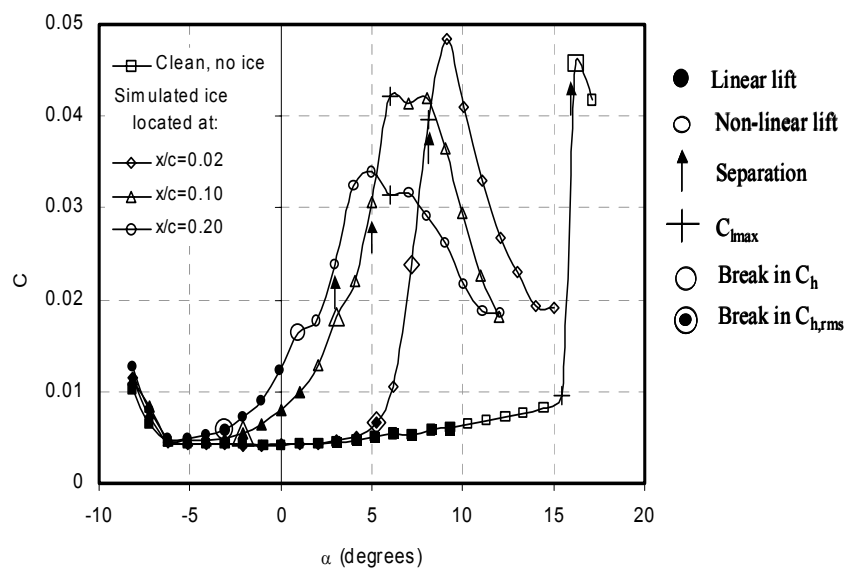

Fig. 6. Unsteady Hinge Moments from Gurbacki ${ }^{15}$

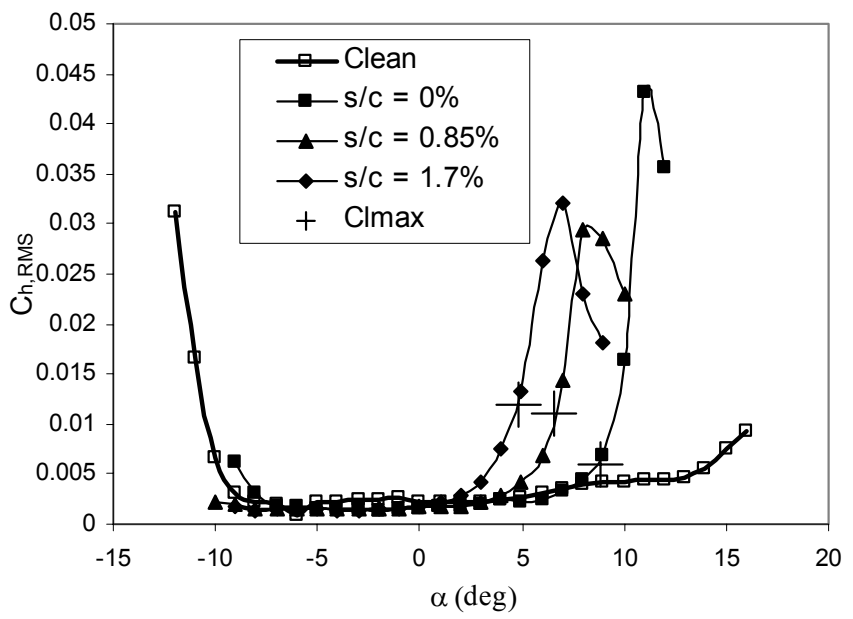

Fig. 7. Comparison of Unsteady Hinge Moments with Simulated Ice Shapes at Different Locations

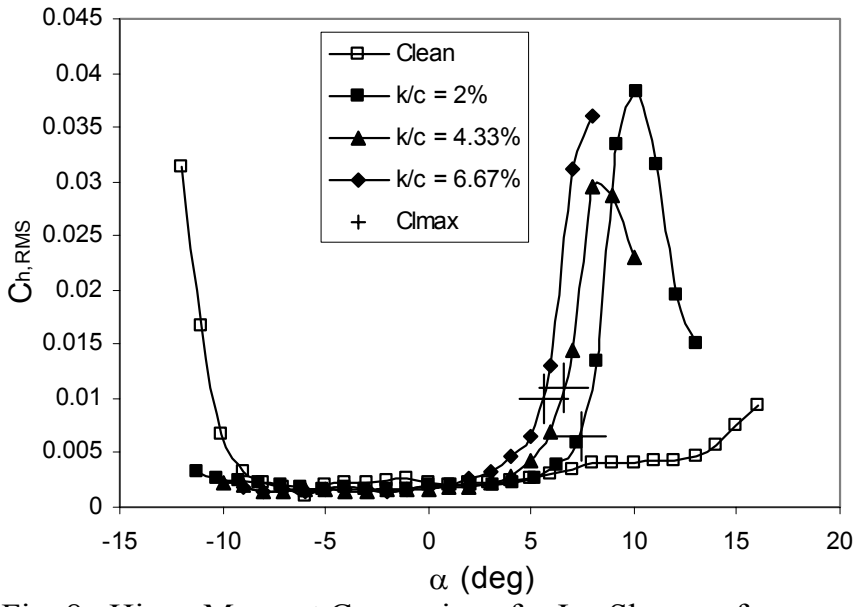

Fig. 8. Hinge Moment Comparison for Ice Shapes of Varying $\mathrm{k} / \mathrm{c}$

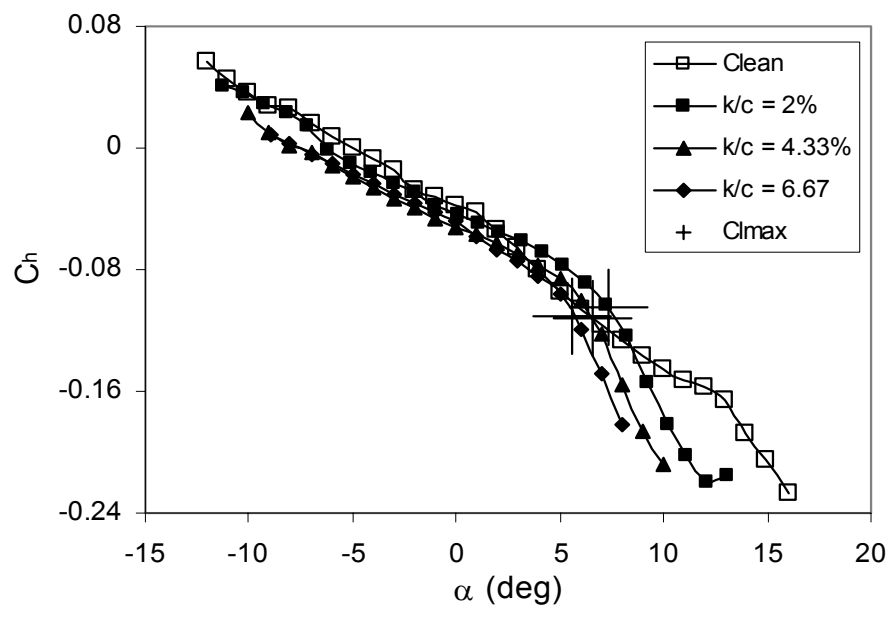

Fig. 9. Steady Hinge Moments for Ice Shapes of Different Sizes

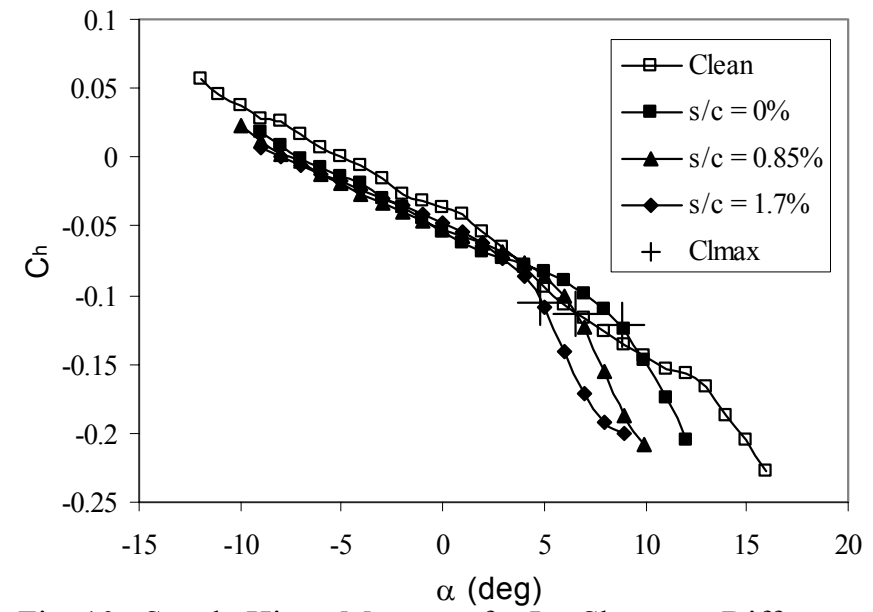

Fig. 10. Steady Hinge Moments for Ice Shapes at Different Locations 


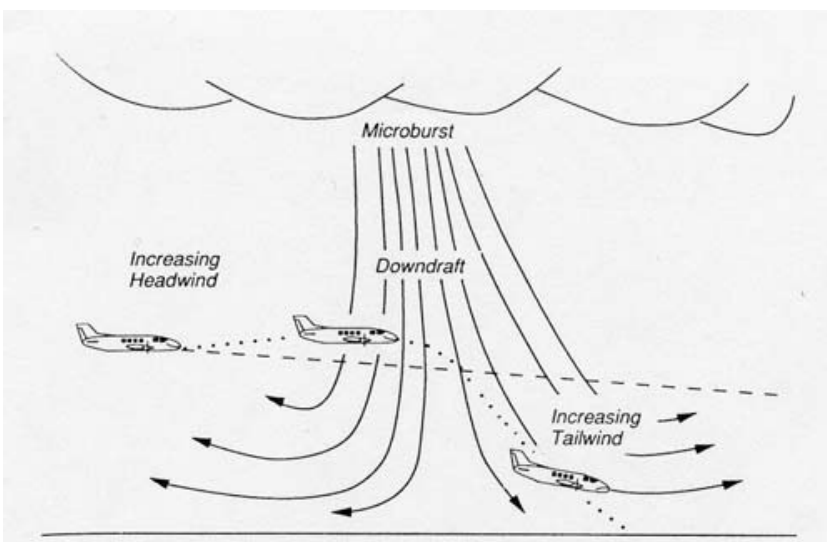

Fig. 11. Microburst encounter during approach to landing ${ }^{18}$

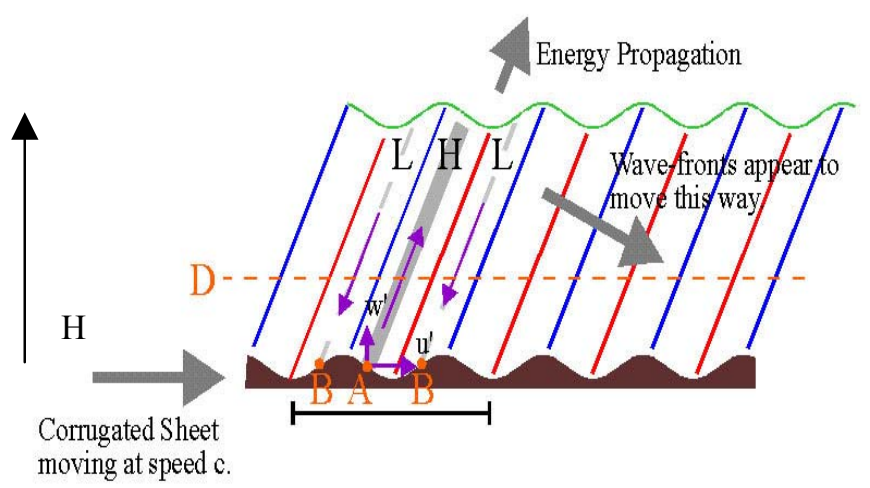

Fig. 12. Corrugated Sheet Wave Schematic ${ }^{19}$

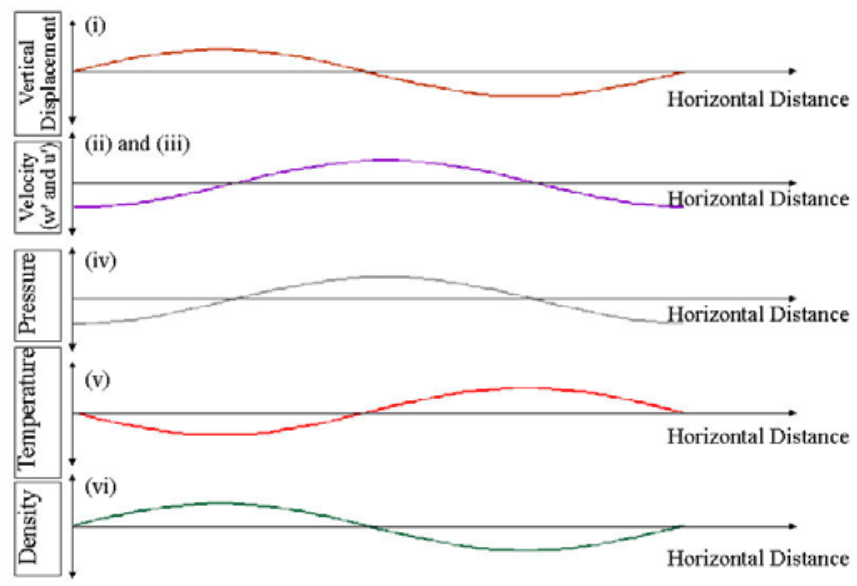

Fig. 13. Wave Parameters Correlation

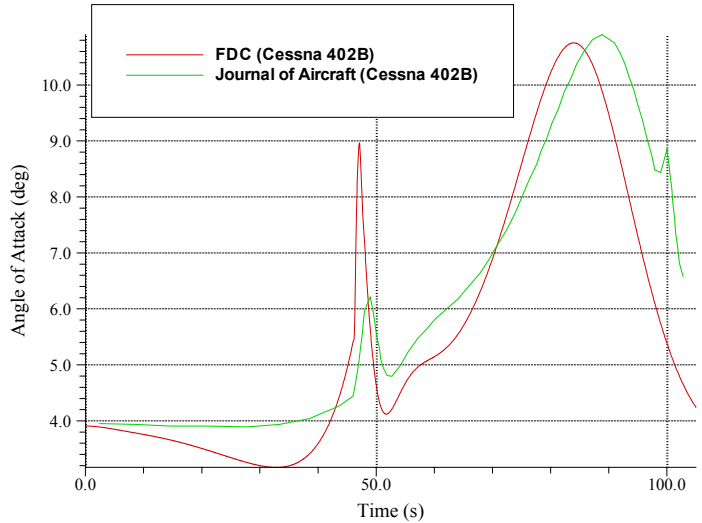

Fig. 14. FDC Microburst Validation

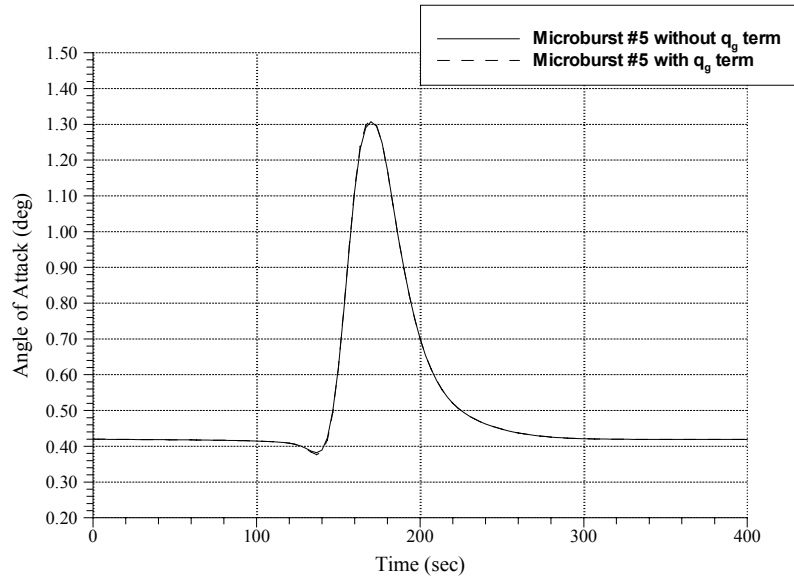

a) Angle of Attack Profile with Closed Loop Autopilot Enabled

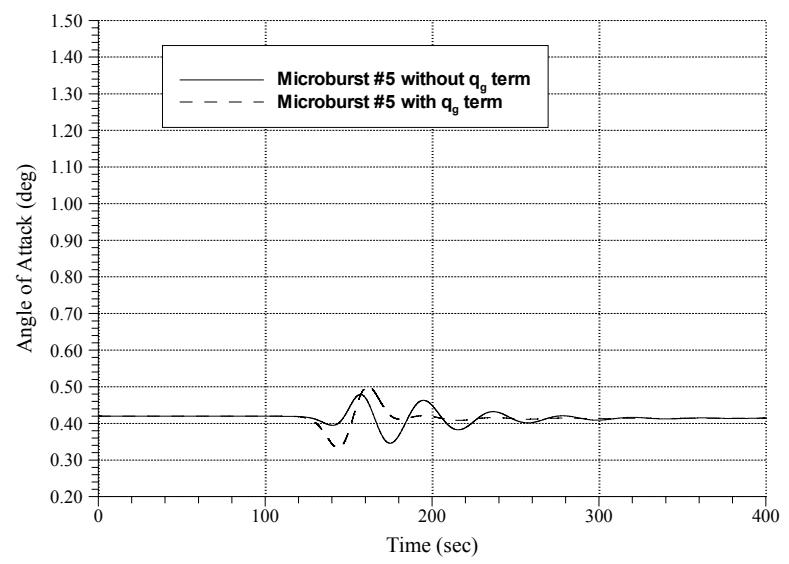

b) Angle of Attack Profile without Autopilot

Fig. 15. Angle of Attack for the Pitch Rate Term 


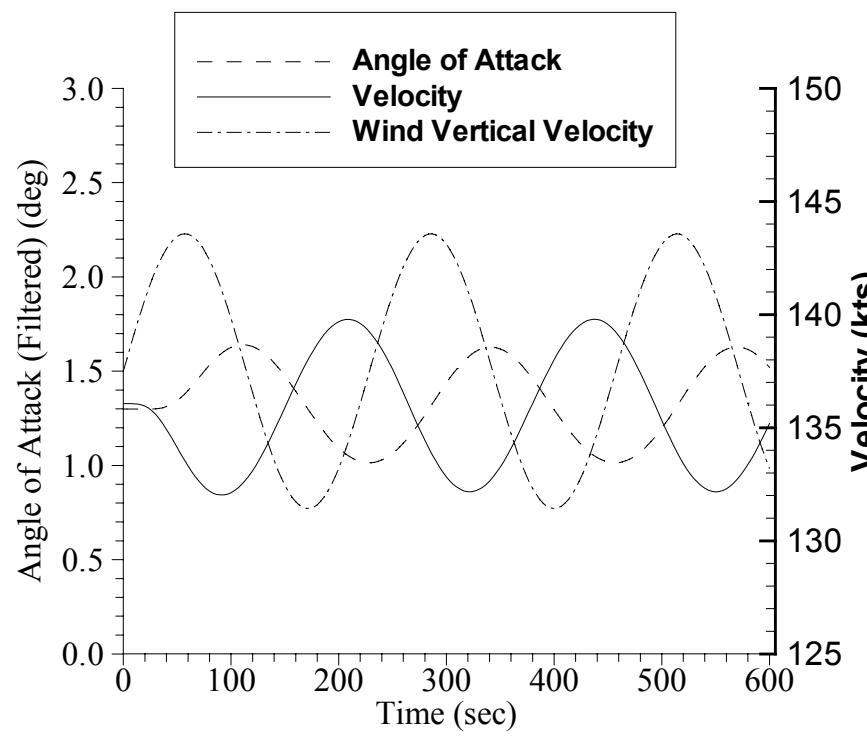

Fig. 16. Phase Relationships for Gravity Waves

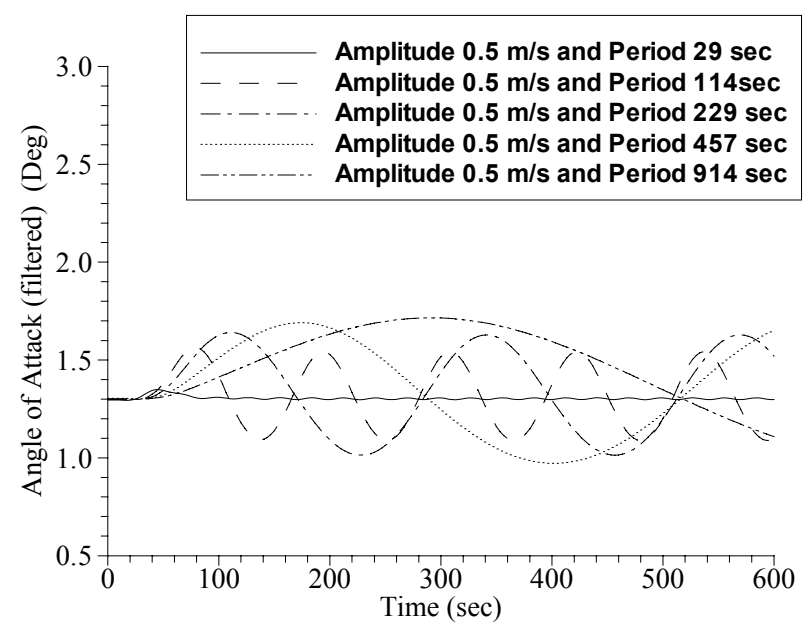

Fig. 17. Angle of Attack for Gravity Waves with Varying Periods

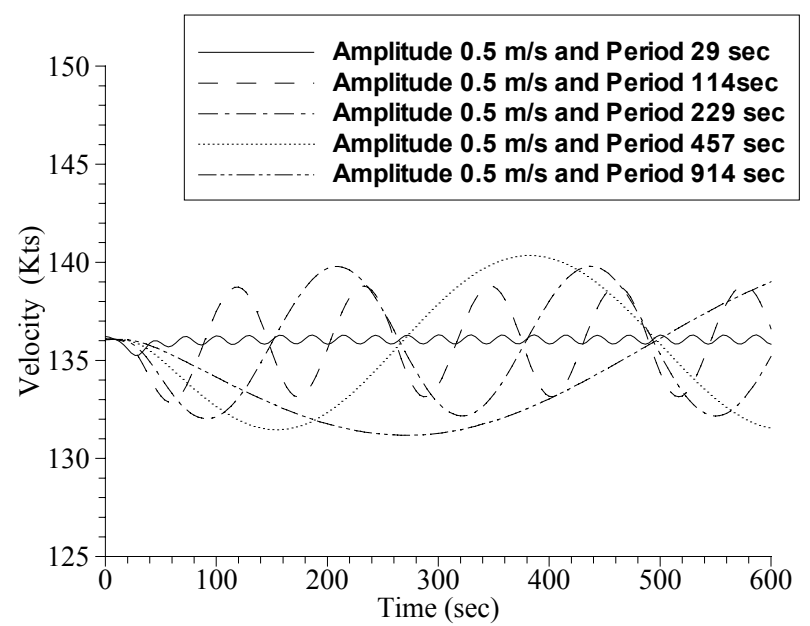

Fig. 18. Velocity for Gravity Waves with Varying Periods

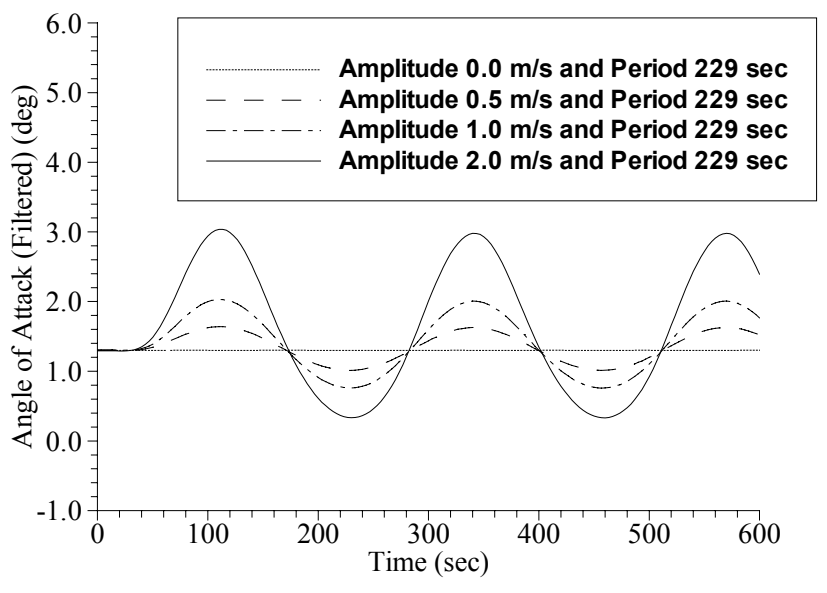

Fig. 19a. Angle of Attack for Varying Gravity Wave Amplitudes (Positive Initialization)

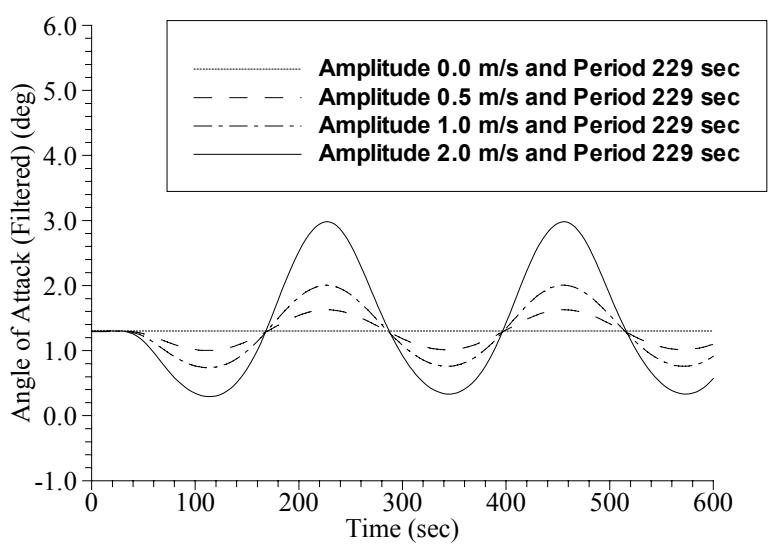

Fig.19b. Angle of Attack for Varying Gravity Wave Amplitudes (Negative Initialization)

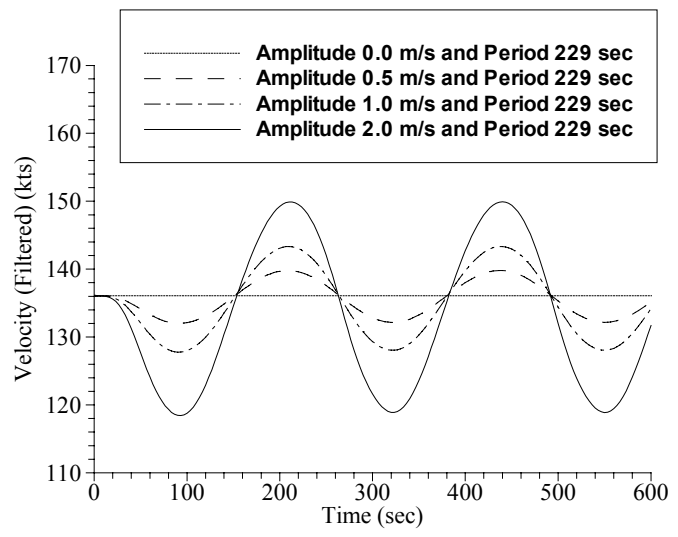

Fig. 20a. Velocity for Varying Gravity Wave Amplitudes (Positive Initialization) 


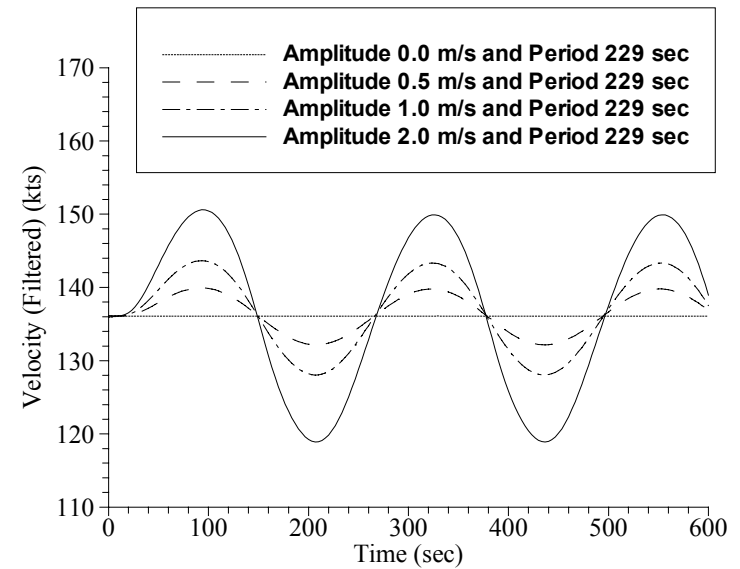

Fig. 20b. Velocity for Varying Gravity Wave Amplitudes (Negative Initialization)

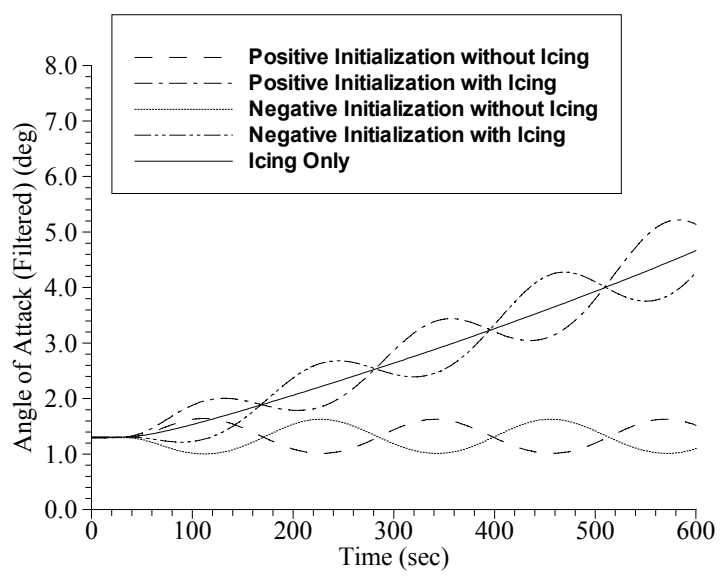

Fig. 21a. Angle of Attack for Gravity Waves and Icing

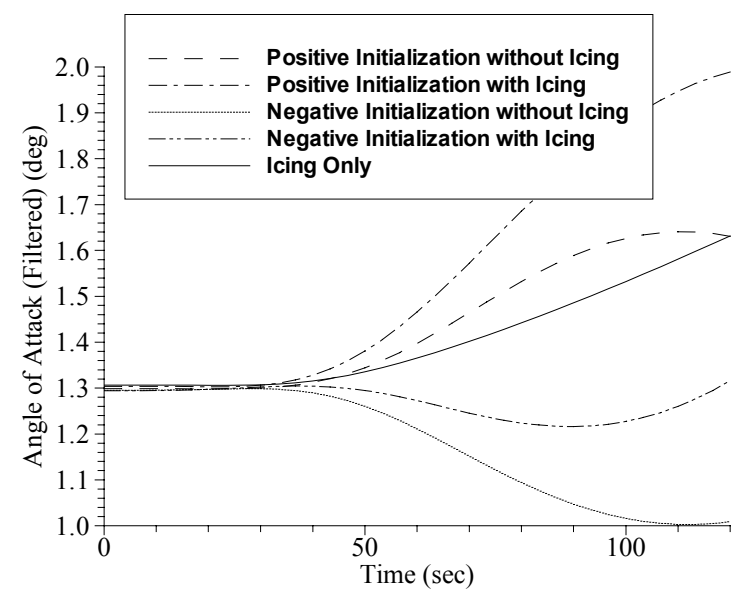

Fig. 21b Angle of Attack for Gravity Waves and Icing (Initialization magnification)

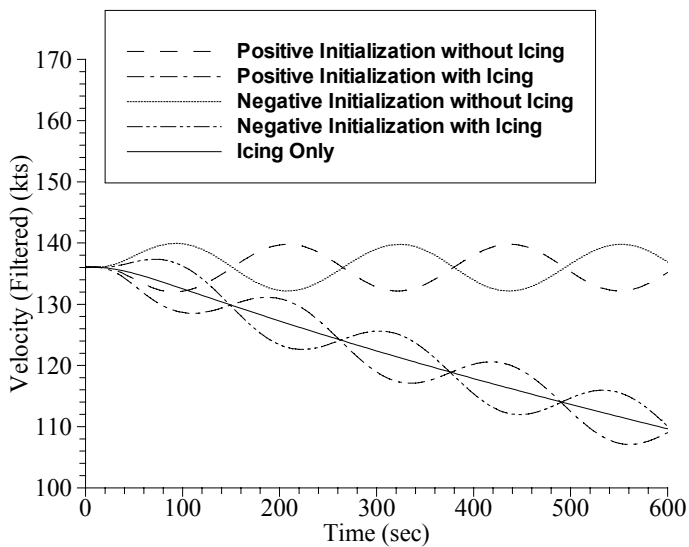

Fig. 22. Velocity for Gravity Waves and Icing

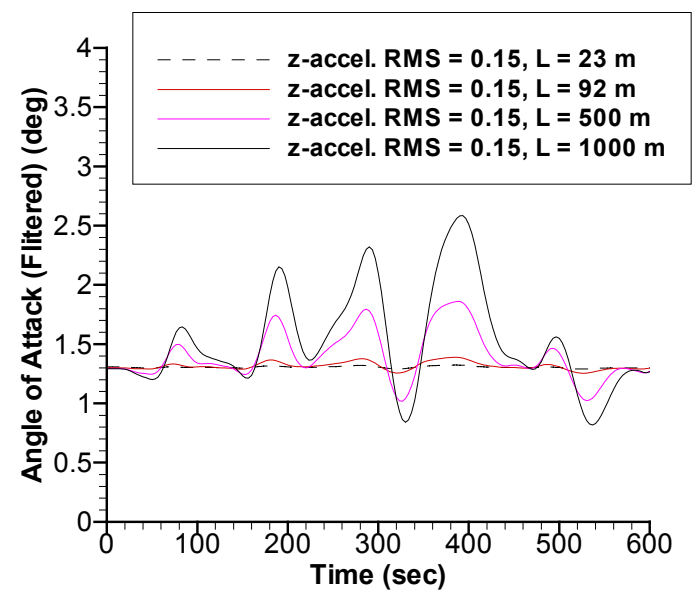

Fig. 23. Angle of Attack for Constant Z-Acceleration RMS $=0.15 \mathrm{~g}$

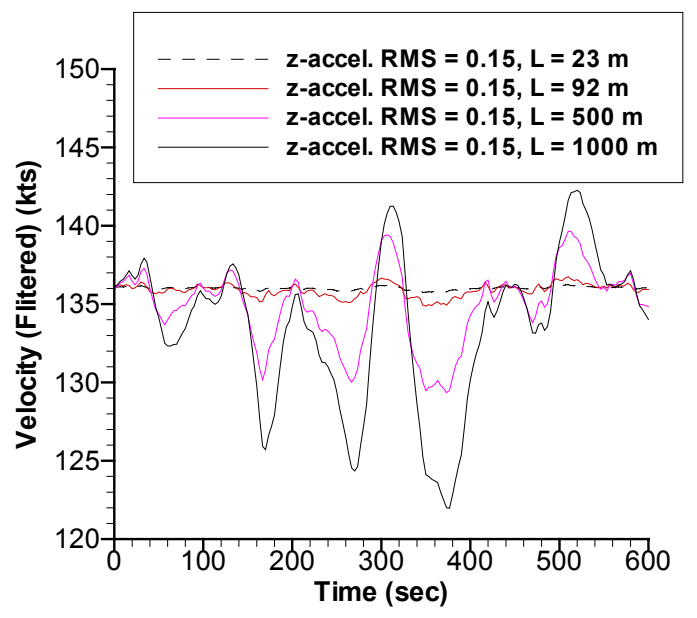

Fig. 24. Velocity for Constant Z-Acceleration RMS $=0.15 \mathrm{~g}$ 


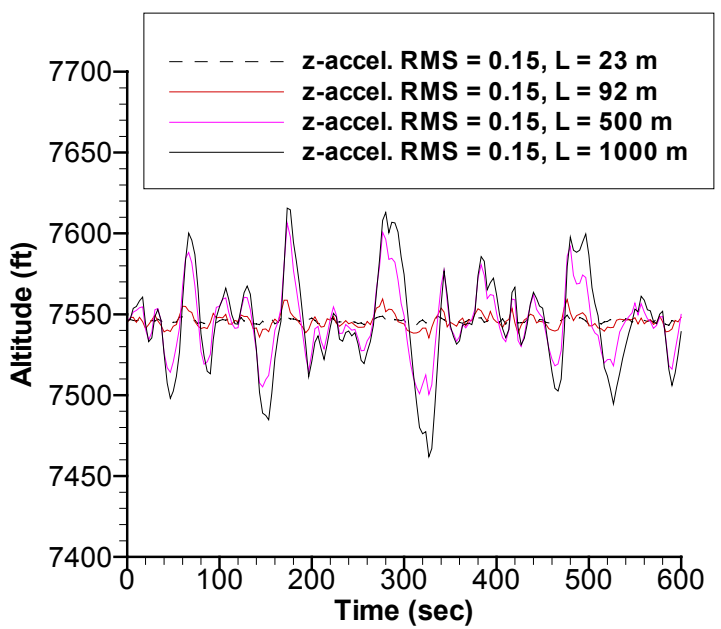

Fig. 25. Altitude for Constant Z-Acceleration RMS $=0.15 \mathrm{~g}$ 